\title{
A speedy route to sterically encumbered, benzene-fused derivatives of privileged, naturally occurring hexahydropyrrolo[1,2-b]isoquinoline
}

\author{
Olga Bakulina, Alexander Ivanov, Vitalii Suslonov, Dmitry Dar'in and Mikhail Krasavin*§
}

\author{
Full Research Paper \\ Address: \\ Institute of Chemistry, Saint Petersburg State University, 26 \\ Universitetsky prospekt, Peterhof 198504, Russia

\section{Email:} \\ Mikhail Krasavin * m.krasavin@spbu.ru \\ * Corresponding author \\ $\S$ ORCID Mikhail Krasavin: 0000-0002-0200-4772 \\ Keywords: \\ Castagnoli-Cushman reaction; diastereoselectivity; homophthalic \\ anhydride; indolenines; lactam synthesis; multicomponent reactions
}

\author{
Beilstein J. Org. Chem. 2017, 13, 1413-1424. \\ doi:10.3762/bjoc. 13.138 \\ Received: 19 May 2017 \\ Accepted: 05 July 2017 \\ Published: 18 July 2017 \\ Associate Editor: T. J. J. Müller \\ (C) 2017 Bakulina et al.; licensee Beilstein-Institut \\ License and terms: see end of document.
}

\begin{abstract}
A series of 15 benzene-fused hexahydropyrrolo[1,2-b]isoquinolonic acids with substantial degree of steric encumbrance has been prepared via a novel variant of the Castagnoli-Cushman reaction of homophthalic anhydride (HPA) and various indolenines. The employment of a special kind of a cyclic imine component reaction allowed, for the first time, isolating a Mannich-type adduct between HPA and an imine component which has been postulated but never obtained in similar reactions.
\end{abstract}

\section{Introduction}

The reaction of imines (prepared in a separate step or generated in situ) with $\alpha-\mathrm{C}-\mathrm{H}$ dicarboxylic acid anhydrides (known as the Castagnoli-Cushman reaction or CCR [1]) offers a direct entry into lactam frameworks 1 of various sizes (traditionally, $\delta$ - and $\gamma$ - [2,3] and, more recently, $\varepsilon$-lactams [4,5]) containing a carboxylic acid functionality. Employment of homophthalic anhydride (HPA) in this reaction delivers medicinally important, most often trans-configured [6,7] tetrahydroisoquinolonic acids 2 (Figure 1) which have found utility as probe compounds or therapeutic agents in diverse areas such as neuroprotection [8], diabetes [9], and cancer [10].
The use of cyclic imines (or surrogates thereof such as isoquinoline [11]) in the CCR is quite scarce in the literature [12-14]. As an example, 1-pyrroline (in the form of its trimer 3) has been reported by Smith and co-workers [15-17] to condense efficiently with HPA analogs to deliver hexahydropyrrolo[1,2$b]$ isoquinolones 4 . The hexahydropyrrolo[1,2-b]isoquinoline core in general is ubiquitous to many natural products exemplified by tylophorine (5) [18], lycorine (6) [19] and its entire family of alkaloids, including zephyranthine (7) [20] and galantine (8) [21]. Considering the plethora of biological activities displayed by the lycorine and tylophorine alkaloids (such as 


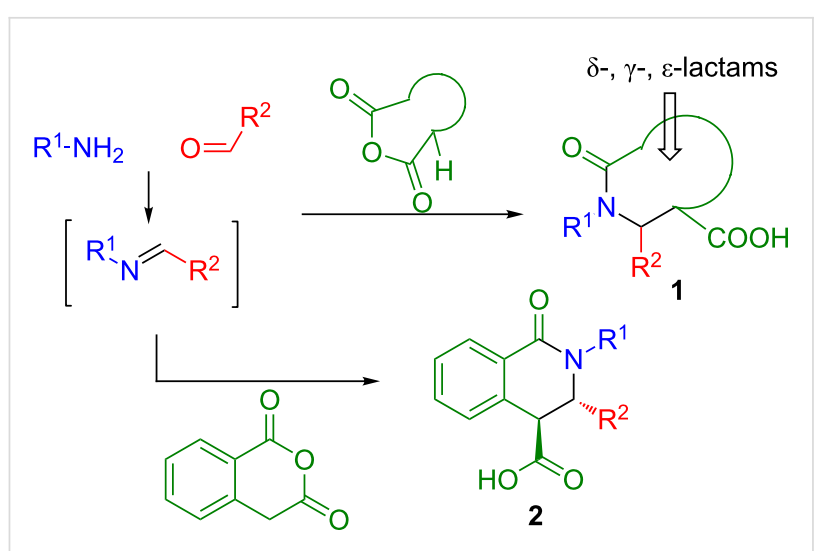

Figure 1: The Castagnoli-Cushman reaction (CCR).

pro-apoptotic [22], antiviral [23], hypoxia-inducible factor-1 inhibitory [24]), the scaffold can be confidently regarded as privileged [25]. Recently, we [26] and others [27] reported the use of indolenines as non-classical inputs for the Joullié-Ugi reaction and for subsequent preparation [28] of sterically encumbered, constrained peptidomimetic frameworks. Diversely substituted indolenines $\mathbf{9}$ are easy to prepare via the Fischer indole synthesis [26] and their use in the CCR can be expected to result in hexahydropyrrolo[1,2-b]isoquinolone derivatives fused with benzene $\mathbf{1 0}$ that have pronounced three- dimensional features and potentially contain several quaternary carbon centers (Figure 2). The first aspect has been recently recognized [29] as a central principle in drug design ensuring effective interaction of small molecules with protein targets and lower off-target effects. The presence of quaternary carbons is characteristic of the natural products domain and is also gaining prominence in medicinal chemistry [30]. Herein, we disclose the results obtained and observations made in the course of our attempt to involve 9 in reactions with HPA. Notably, due to its non-planar tetracyclic character, the hexahydropyrrolo[1,2$b$ ]isoquinolone fused with benzene scaffold (present in 10) clearly appears related to (though topologically distinct from) the natural and synthetic camptothecin-like topoisomerase inhibitors [31].

\section{Results and Discussion}

The study commenced with the synthesis of set of 2-H as well as 2-substituted indolenines $\mathbf{9 a - t}$ using a previously published procedure (Figure 3) [26]. Acetonitrile was previously found [32] to be an effective solvent promoting the CCR of HPA with acyclic amines at room temperature. As it also facilitated the isolation of the tetrahydroisoquinolonic acid product, it was chosen to study the CCR of $\mathbf{9 a - t}$. The latter tend to precipitate in a pure form (often as a single diastereomer) from the reaction mixture and can be conveniently isolated by filtration. This

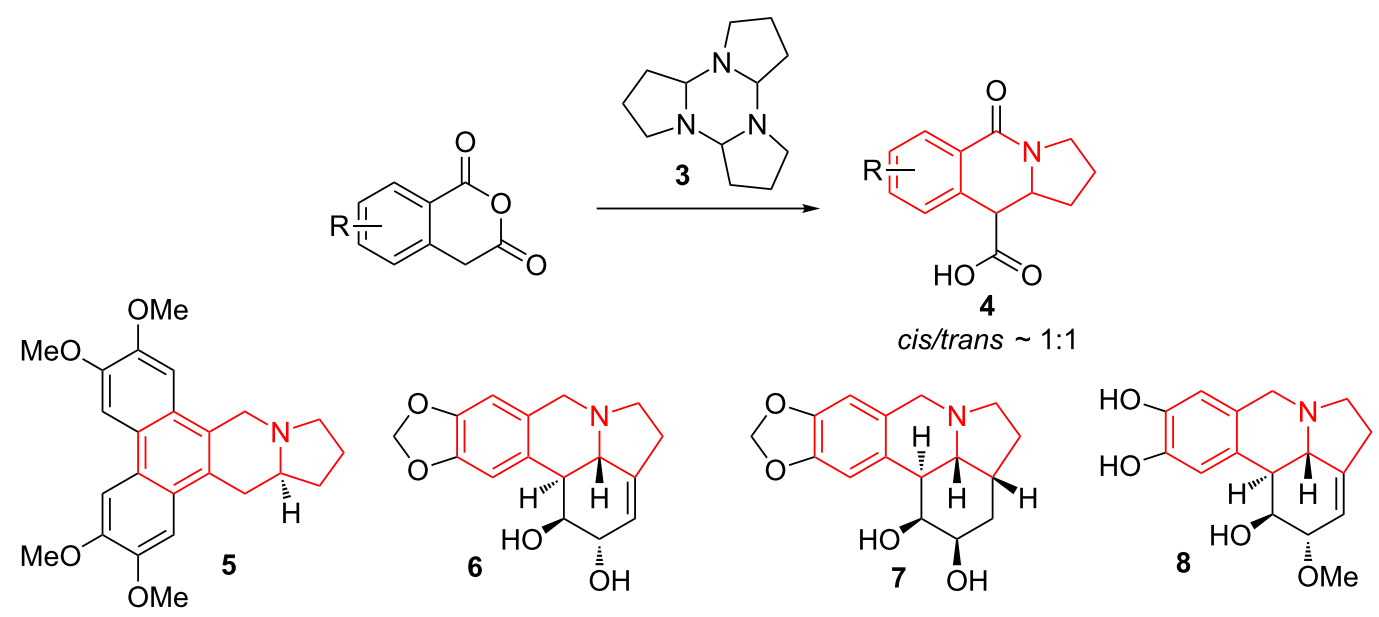

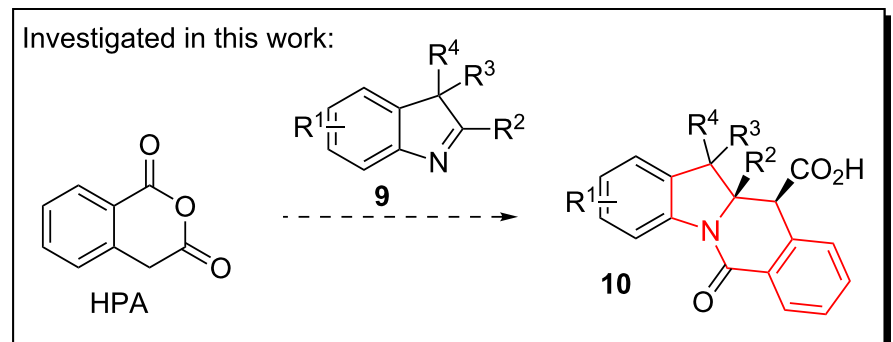




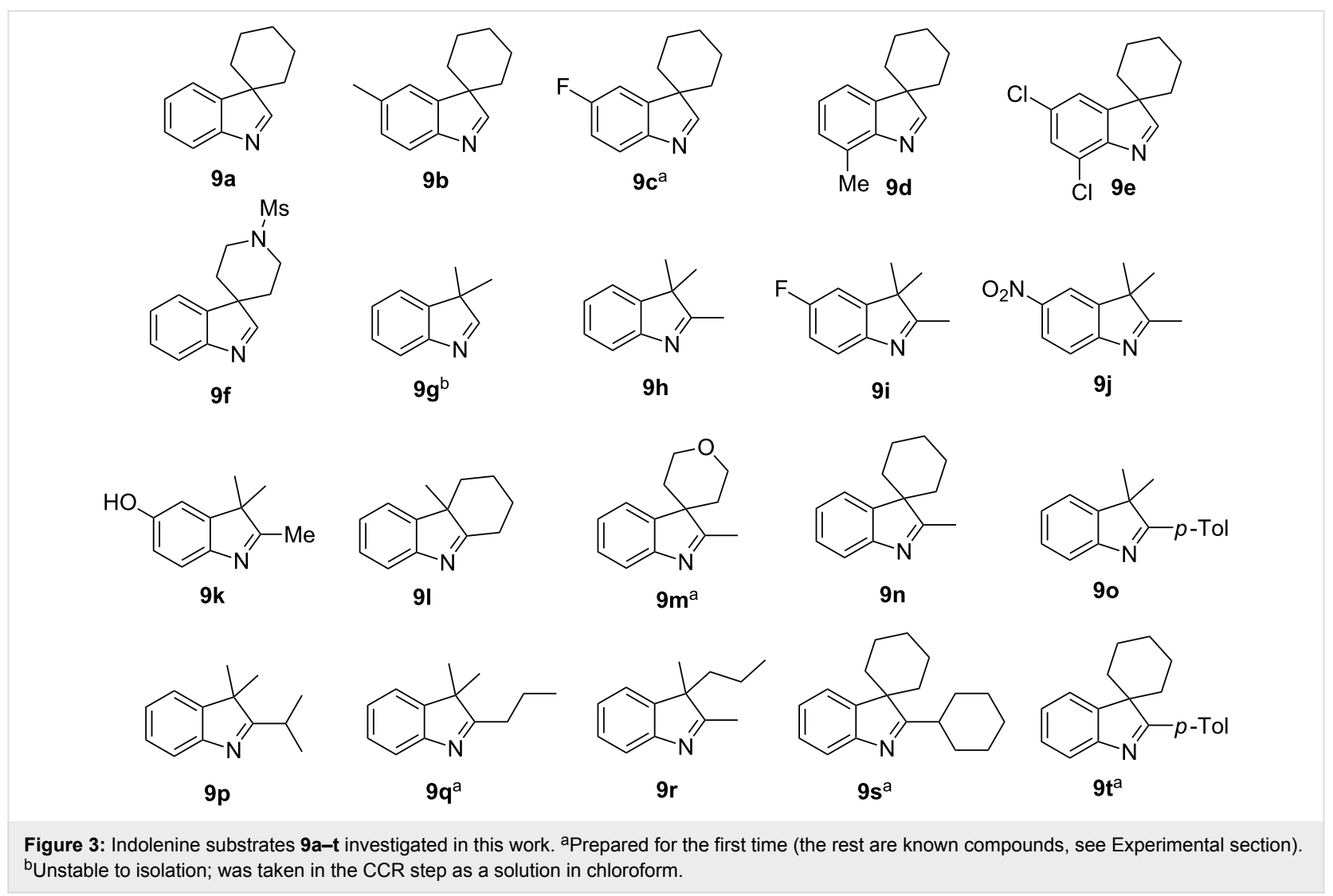

prior observation also held true for the reaction between HPA and most of indolenines 9 .

As shown in Table 1, all of the 2-unsubstituted indolenines 9a-g and many 2-substituted one $\mathbf{9 h - 0}$ furnished the expected respective tetracyclic tetrahydroisoquinolonic acids $\mathbf{1 0}$ on treatment with HPA (1.0 equiv) in acetonitrile $(2 \mathrm{~mL} / \mathrm{mmol})$ Notably, when the CCR with HPA was repeated for $\mathbf{9 h}$ in other solvents (toluene, chloroform or DMF) at room temperature, this resulted in a similar product yield and diastereomeric ratio. However, the isolation of $\mathbf{1 0 h}$ from the respective reaction mixtures was distinctly cumbersome, which only confirmed acetonitrile to be the solvent of choice for these reactions.

A number of observations emerged from examination of the results in Table 1. In all cases (except entry 7 where carboxylic acid $10 \mathrm{~g}$ did not precipitate from the reaction mixture and was isolated as respective methyl ester $\left.\mathbf{1 0} \mathbf{g}^{\prime}\right)$, the major diastereomer was shown to possess the $(R S, R S)$-configuration (vide infra) and is referred to as ' $a n t i^{\text {' }}$ throughout this article (considering orientation of carboxylic group relative to $\mathrm{C}^{11 \mathrm{a}-\mathrm{C}^{12}}$ bond of the five-membered ring); the minor, $(R S, S R)$-configured diastereomer is referred to as 'syn' (Figure 4). A good to excellent yield of pure anti-diastereomer was obtained with $\mathbf{9 a}, \mathbf{b}, \mathbf{9 d}, \mathbf{9 j}$
91, 9n,o (Table 1, entries 1, 2, 4, 10, 12, 14 and 15) by simple filtration. We have also shown that in some of these cases (Table 1, entries 1 and 2) an additional quantity of anti- and/or syn-configured CCR product could be recovered from the filtrate in the form of respective methyl esters after $O$-methylation and chromatographic separation (see Experimental section): syn-10a' (7\%), anti-10a' (12\%), syn-10b' (13\%). In those cases when the carboxylic acid precipitate contained a significant proportion of the syn-configured CCR product (Table 1, entries 3, 8, 11 and 13, anti/syn ratio ranging from $3.3: 1$ to $6.5: 1$ ), the latter was removed by crystallization and the respective pure anti-diastereomers (anti-10c, 10h, 10k and $10 \mathrm{~m})$ were obtained and characterized. In certain instances (Table 1, entries 5-7, and 9), isolation of pure diastereomeric CCR adducts was achieved by total esterification of the carboxylic acid product mixture and chromatographic separation of the respective methyl esters (the $0.8: 1$ anti/syn-10e mixture stereoconverged to anti-10e' on esterification, vide infra).

The trans-diastereoselectivity of the CCR is well documented in the literature [33] and is, therefore, unsurprising. However, the stereocontrol achieved in this reaction over 3 stereocenters present in $\mathbf{1 0 1}$ (obtained in $81 \%$ yield as a single diastereomer) is certainly quite noteworthy and was confirmed by X-ray analysis (Figure 5). 
Table 1: Indolo[1,2-b]isoquinolonic acids 10 obtained via the CCR of indolenines 9

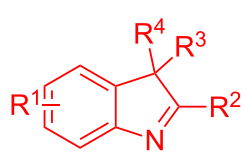

9

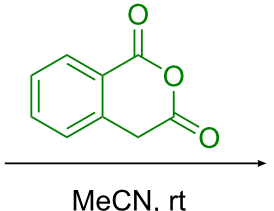

$\mathrm{MeCN}, \mathrm{rt}$<smiles>[R]C1([R2])c2cc[R1]cc2N2C(=O)c3ccccc3C(C(=O)O)C21[R]</smiles>

\begin{tabular}{|c|c|c|c|c|c|}
\hline Entry & 9 & Product 10 & Time & Isolated yield, $\%^{a}$ & anti/syn \\
\hline 1 & $9 a$ & & $2 \mathrm{~h}$ & 56 & $>20: 1^{b}$ \\
\hline 2 & $9 b$ & & $2 \mathrm{~h}$ & 73 & $>20: 1^{b}$ \\
\hline 3 & $9 c$ & & $24 \mathrm{~h}$ & 66 & $3.3: 1^{\mathrm{c}}$ \\
\hline 4 & $9 d$ & & $3 \mathrm{~h}$ & 84 & $>20: 1$ \\
\hline 5 & $9 e$ & & $48 \mathrm{~h}$ & 66 & $0.8: 1^{d}$ \\
\hline 6 & $9 f$ & & $72 \mathrm{~h}$ & 79 & $2: 1^{d}$ \\
\hline
\end{tabular}


Table 1: Indolo[1,2-b]isoquinolonic acids 10 obtained via the CCR of indolenines 9 . (continued)

7

$9 g$<smiles>CC(=O)C1c2ccccc2C(=O)N2c3ccccc3C(C)(C)C12C</smiles>

10g'<smiles>CC(C)(C)c1ccccc1N1C(=O)c2ccccc2C(C(=O)O)C1(C)C</smiles>

$10 \mathrm{~h}$<smiles>CC1(C)c2cc(F)ccc2N2C(=O)c3ccccc3C(C(=O)O)C21C</smiles>

$10 \mathrm{i}$<smiles>CC(C)C12C(C)c3ccccc3C(=O)N1c1ccc([N+](=O)[O-])cc1C2(C)C</smiles>

10j<smiles>CC1(C)c2cc(O)ccc2N2C(=O)c3ccccc3C(C(=O)O)C2(C)C1(C)C</smiles>

10k

12

91<smiles>CC12CCCCC13C(=O)N1c4ccccc4C(=O)N(c4ccccc41)C23C(=O)O</smiles>

13

$9 m$

14

9n<smiles>CC(=O)C1c2ccccc2C(=O)N2c3ccccc3C3(CCOCC3)C12C(C)=O</smiles>

$72 \mathrm{~h}$

$25 d$
87

$1.4: 1^{d}$

$16 \mathrm{~h}$

$48 \mathrm{~h}$

$48 \mathrm{~h}$

73

$>20: 1$

$48 \mathrm{~h}$

57

$6.5: 1^{\mathrm{c}}$

$48 \mathrm{~h}$

81

$>20: 1$

79

$6: 1^{c}$

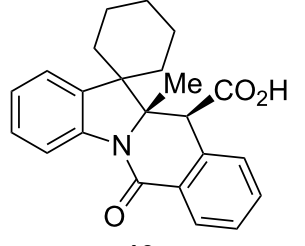

10n 
Table 1: Indolo[1,2-b]isoquinolonic acids 10 obtained via the CCR of indolenines 9. (continued)

15

90

$\begin{array}{ll}16 & 9 p \\ 17 & 9 q \\ 18 & 9 r \\ 19 & 9 s \\ 20 & 9 t\end{array}$<smiles>CC1(C)c2ccccc2N2C(=O)c3ccccc3C(C(=O)O)C21C(=O)O</smiles>

$50 \mathrm{~d}$

$-$

$-$

asolated yield of the product precipitate from the reaction mixture. ${ }^{b}$ Additional quantity of the anti- and/or syn-diastereomer(s) isolated from the filtrate as respective methyl esters 10' (see Experimental section). 'Pure anti-diastereomer obtained by crystallization. 'Isolated and characterized as respective methyl esters $\mathbf{1 0}^{\prime}$.

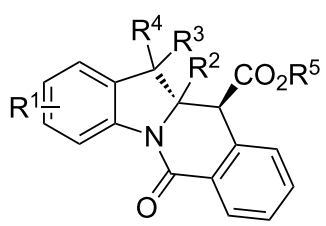

$R S, R S-10$ ("anti"-10), $\mathrm{R}^{5}=\mathrm{H}$ $R S, R S-10 '$ ("anti"-10'), $\mathrm{R}^{5}=\mathrm{Me}$<smiles>[R]C1([R2])c2cc[R1]cc2N2C(=O)c3ccccc3C(C(=O)O)C21[R]</smiles>

$R S, S R-10$ ("syn"-10), $\mathrm{R}^{5}=\mathrm{H}$

$R S, S R-10 '$ ("syn"-10'), $\mathrm{R}^{5}=\mathrm{M \epsilon}$

Figure 4: Anti- and syn-diastereomers of 10 and 10'.

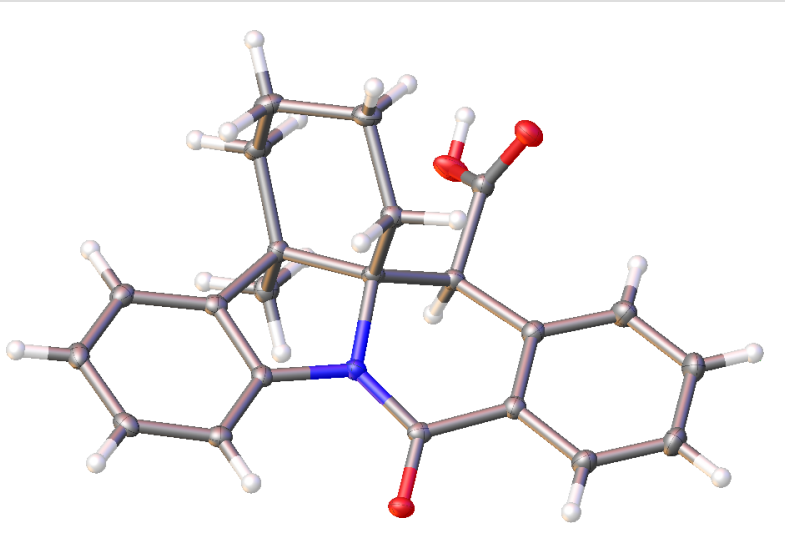

Figure 5: Single-crystal X-ray structure of compound 101.

The tolerance of the reaction to the substitution pattern in the aromatic portion of the indolenines appears rather broad, both in terms of the electronic character of substituents and steric effects - although substituents in position 7 of the indolenine significantly affect the conformational behavior of the respective CCR adducts 10d,e (vide infra). Notably, free phenolic hydroxy function is well tolerated $(\mathbf{9 k} \rightarrow \mathbf{1 0 k})$ which is in line with literature reports [33]. However, the steric situation around the five-membered ring of indolenines had a profound effect on the reaction times and even the ability of certain indolenines to act as competent partners in the CCR. 2-Substituted indolenines 9h-o required significantly longer times (from $16 \mathrm{~h}$ to 50 days) to be converted to the respective CCR products, compared to their 2-unsubstituted counterparts. Indolenines $\mathbf{9 p - t}$ failed to undergo the reaction with HPA either at rt or at reflux temperature in acetonitrile or toluene. Attempts to trigger the reaction with these substrates by excluding solvent altogether [34] or applying microwave irradiation (up to $2 \mathrm{~h}$ at $200{ }^{\circ} \mathrm{C}$ in $\mathrm{MeCN}$ ) were also unsuccessful. Any appreciable conversion led to predominant formation of HPA dimer 11 and product of its decarboxylation 12 (Scheme 1). The formation of these two products (observed by ${ }^{1} \mathrm{H}$ NMR) was recently reported by Knapp et al. [35] as a result from the treatment of HPA with a strong base (which was absent in our case). The failure to activate sterically hindered indolenines toward the CCR using forcing conditions justifies conducting the reaction at room temperature, which led to clean conversions and good product yields despite the excruciatingly long reaction times (Table 1, entries 14 and 15). 
<smiles>[R]C1=Nc2ccccc2C1([R])[R]</smiles>

$9 p-t$

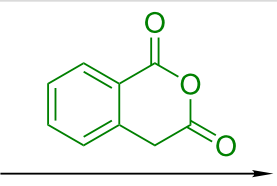<smiles>O=C(O)c1ccccc1Cc1oc(=O)c2ccccc2c1C(=O)O</smiles>

11<smiles>O=C(O)c1ccccc1Cc1cc2ccccc2c(=O)o1</smiles>

12

Scheme 1: Formation of unwanted products 11 and 12 in lieu of the CCR with $9 p-t$.

In order to ensure a correct stereochemical assignment of all major (anti) and minor (syn) products obtained in the reactions discussed herein, we obtained single-crystal X-ray structures of sixteen CCR adducts synthesized in this work and correlated this structural information with the NMR behavior of these compounds. The range of the coupling constant $J\left(\mathrm{H}^{11}-\mathrm{H}^{11 \mathrm{a}}\right)$ values appears a straightforward criterion for relative stereochemistry assignment in compounds $\mathbf{1 0}$ derived from $2 H$-indolenines. As summarized in Figure 6 (see also Table S1 in Supporting Information File 1), anti-diastereomers display this coupling constant around $13 \mathrm{~Hz}$, while it is in the $3-4 \mathrm{~Hz}$ range for $s y n$-isomers.

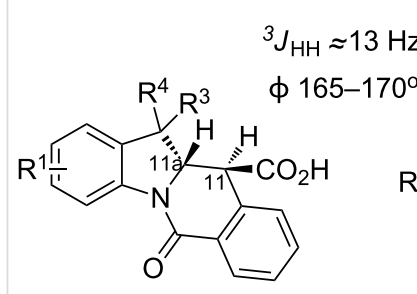

anti-10

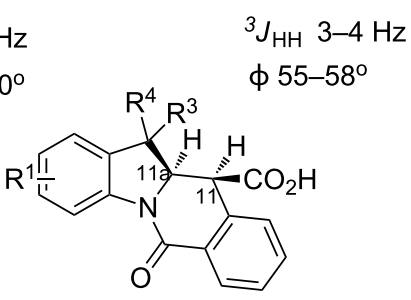

syn-10
Figure 6: Typical $J\left(\mathrm{H}^{11}-\mathrm{H}^{11 a}\right)$-values and corresponding dihedral angles for syn- and anti-diastereomers of compounds $\mathbf{1 0}$ derived from $2 \mathrm{H}$-indolenines.

According to the $\mathrm{X}$-ray analysis, the dihedral angle values in the $\mathrm{C}^{11} \mathrm{H}-\mathrm{C}^{11 \mathrm{a}} \mathrm{H}$ fragment lie within the $165-170^{\circ}$ and $55-58^{\circ}$ range for anti- and syn-diastereomers, respectively (Supporting Information File 1, Table S1). Thus, for most of the $2 \mathrm{H}$-indolenine-derived compounds (except for 10d,e), there appears to be a good correlation between the relative stereochemistry of $\mathbf{1 0}, J\left(\mathrm{H}^{11}-\mathrm{H}^{11 \mathrm{a}}\right)$ values observed in the ${ }^{1} \mathrm{H}$ NMR spectra of their solutions and said dihedral angle in crystals. Surprisingly, compounds 10d,e (derived from more sterically congested 7-substituted indolenines 9d,e) display the $J\left(\mathrm{H}^{11}-\mathrm{H}^{11 \mathrm{a}}\right)$ values of $3.0 \mathrm{~Hz}$ for both diastereomers, which is inconsistent with the regular values of corresponding dihedral angles $\left(166.3^{\circ}\right.$ and $169.7^{\circ}$ for anti-10d and anti-10e, respectively; $57.5^{\circ}$ for $\left.s y n-10 \mathrm{e}\right)$ measurable in the X-ray structures of these compounds. We reasoned that such a phenomenon could be rationalized by a different conformer population in the solution compared to solid state. This hypothesis was preliminary confirmed by the results of variable-temperature NMR experiments summarized in Supporting Information File 1 (Figures S1-S6). Another potentially useful criterion for stereochemistry assignment of compounds $\mathbf{1 0}$ derived from 2-methylindolenines $10 \mathbf{h}-\mathbf{k}, \mathbf{1 0 m}, \mathbf{n}$ is the range of ${ }^{13} \mathrm{C}$ chemical shifts observed for the angular methyl group in their syn- and anti-diastereomers (Supporting Information File 1, Figure 7, Table S2). These findings were also verified by the available X-ray information on these compounds. Finally, the relative stereochemistry of compound $\mathbf{1 0 0}$ (for which neither X-ray structures nor reliable NMR criteria were available) was assigned on the basis of the through-space interactions observable in its NOESY spectrum and the value of a ${ }^{3} J_{\mathrm{CH}}$ coupling constant (Supporting Information File 1, Figure 8, Figures S7-9).

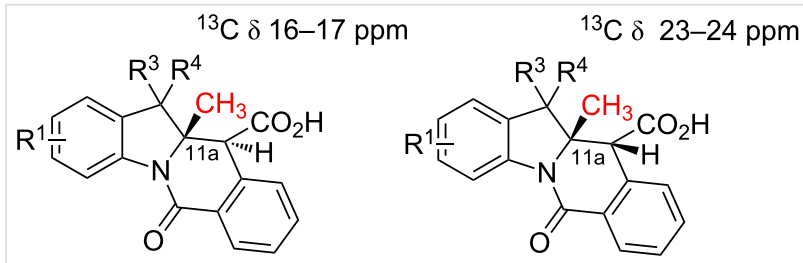

Figure 7: The difference in the ${ }^{13} \mathrm{C}$ NMR chemical shifts of the angular methyl group between syn- and anti-diastereomers of 11a-Me in compounds $10 \mathrm{~h}-\mathrm{k}, 10 \mathrm{~m}, \mathrm{n}$.

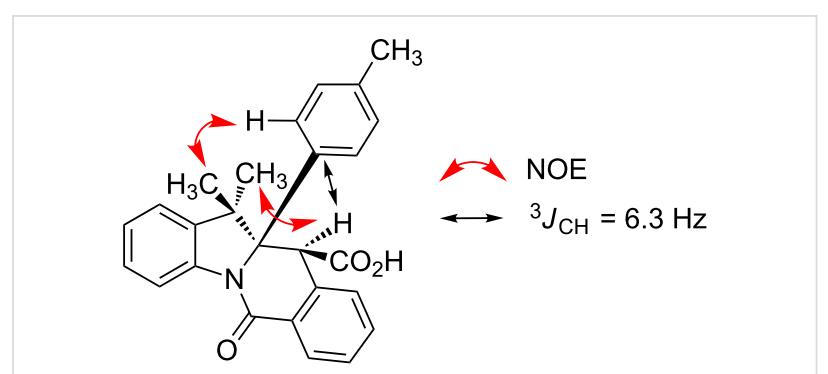

Figure 8: Criteria for stereochemistry assignment of anti-10o.

Besides the anomalous NMR behavior discussed above, compound 10e displayed a number of unusual tendencies which may shed some light on the diastereomeric integrity of CCR 
adducts in general as well as on the mechanism of their formation. Compound 10e initially formed as a 0.8:1 mixture of anti/ syn diastereomers (Table 1). However, it was promptly noted that this mixture converges to thermodynamically more stable anti-10e (the isomerization occurs on heating to $80{ }^{\circ} \mathrm{C}$ or, more slowly, even at room temperature). Esterification of anti/syn10e in the presence of potassium carbonate led to the formation of anti-10e' as a sole product, presumably, via a base-promoted enolization and subsequent isomerization of the syn-10e (10e', Scheme 2).

Enolization is thought to be a key event in the formation of the CCR products which can occur via two alternative mechanisms: (a) $\mathrm{N}$-acylation of the imine component followed by intramolecular Mannich reaction or (b) Mannich-type addition of the HPA enolate to a protonated imine component followed by intramolecular aminolysis of the cyclic anhydride moiety in Mannich adduct 13 (Scheme 3) [1].

Investigation of the CCR leading to the formation of 10e undertaken in this work led to a serendipitous important observation that exposure of 9e to an equimolar amount of HPA in acetonitrile at low temperature $\left(5^{\circ} \mathrm{C}\right)$ and higher dilution (two-fold compared to that used throughout this study) over 2 days led to a predominant formation of the respective Mannich adduct 13e which crystallized out as a single diastereomer from the reaction mixture along with syn/anti-10e mixture and was separated from the latter mechanically under a microscope. Adduct 13e (which has been postulated in the literature as a principal intermediate in the CCR $[1,28]$ but never isolated) was characterized by means of ${ }^{1} \mathrm{H}$ and ${ }^{13} \mathrm{C}$ NMR spectroscopy as well as $\mathrm{X}$-ray crystallography. The isolation, for the first time, of the Mannich-type adduct $\mathbf{1 3}$ between HPA and an imine clearly attests to the viability of mechanistic pathway (b) shown in Scheme 3 .

When left at room temperature for $12 \mathrm{~h}$ as a solution in $\mathrm{CDCl}_{3}$, single diastereomer 13e fully converted itself into a ca. 1:1 anti/ syn-10e (Scheme 4).

Conversion of diastereomerically pure 13e into a mixture of diastereomers can be rationalized by a faster formation of<smiles></smiles>

$80^{\circ} \mathrm{C}, 26 \mathrm{~h}$ - anti/syn $10 \mathrm{e} 1.7: 1.0$ $25^{\circ} \mathrm{C}, 3$ months - anti/syn 10e 1.0:0<smiles>O=C(O)C1c2ccccc2C(=O)N2c3c(Cl)cc(Cl)cc3C13CCCCC23</smiles>

$10 \mathrm{e}$ anti/syn 0.8:1

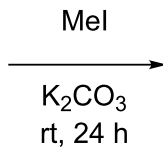<smiles>COC1c2ccccc2C(=O)N2c3c(Cl)cc(Cl)cc3C3(CCCCC3)[C@H]12</smiles>

$10 e^{\prime}, 75 \%$<smiles>[R]C=[N+]([R])C[R]</smiles> 


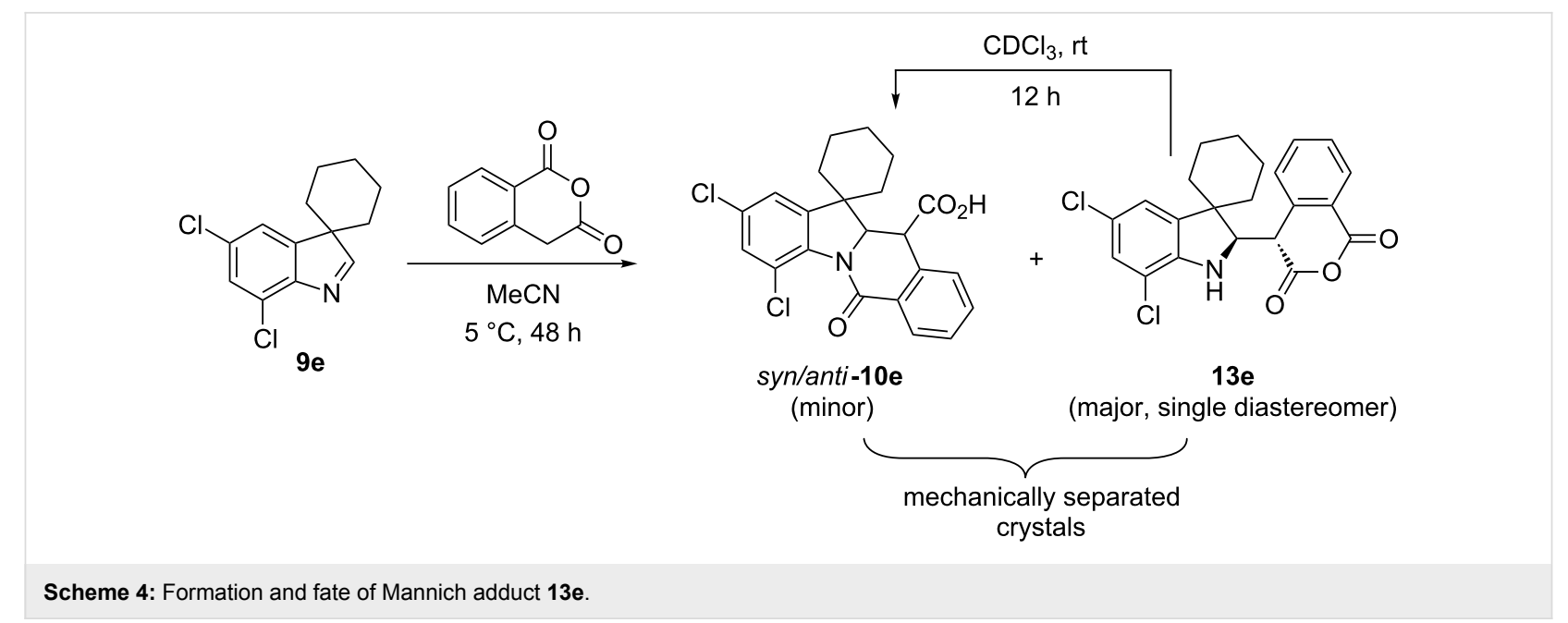

kinetic product $s y n-\mathbf{1 0 e}$ preceded by enolization, in competition with direct albeit slow conversion $\mathbf{1 3 e} \rightarrow$ anti-10e (Scheme 5).

We mentioned that tetracyclic compounds $\mathbf{1 0}$ carry resemblance to natural as well as synthetic camptothecin-like topoisomerase inhibitors (vide supra). Compounds $\mathbf{1 0}$ are endowed with HPA-derived carboxylic acid functionality which may facilitate or prevent compounds' binding to DNA or DNA-topoisomerase complex. Depending on the medicinal chemistry context, compounds $\mathbf{1 0}$ can be decarboxylated to deliver steri- cally encumbered tetracyclic lactams $\mathbf{1 4}$ lacking the carboxylic acid group as we showed for exemplary compound $\mathbf{1 0 h}$. The 4.3:1 anti/syn mixture of diastereomers of $\mathbf{1 0 h}$ rapidly and cleanly lost the carboxylic function at $200{ }^{\circ} \mathrm{C}$ and gave $83 \%$ yield of racemic compound $\mathbf{1 4 h}$ (Scheme 6 ).

\section{Conclusion}

We have described a novel variant of the Castagnoli-Cushman reaction employing indolenines as cyclic imine components in the reaction with homophthalic anhydride (HPA). The com-

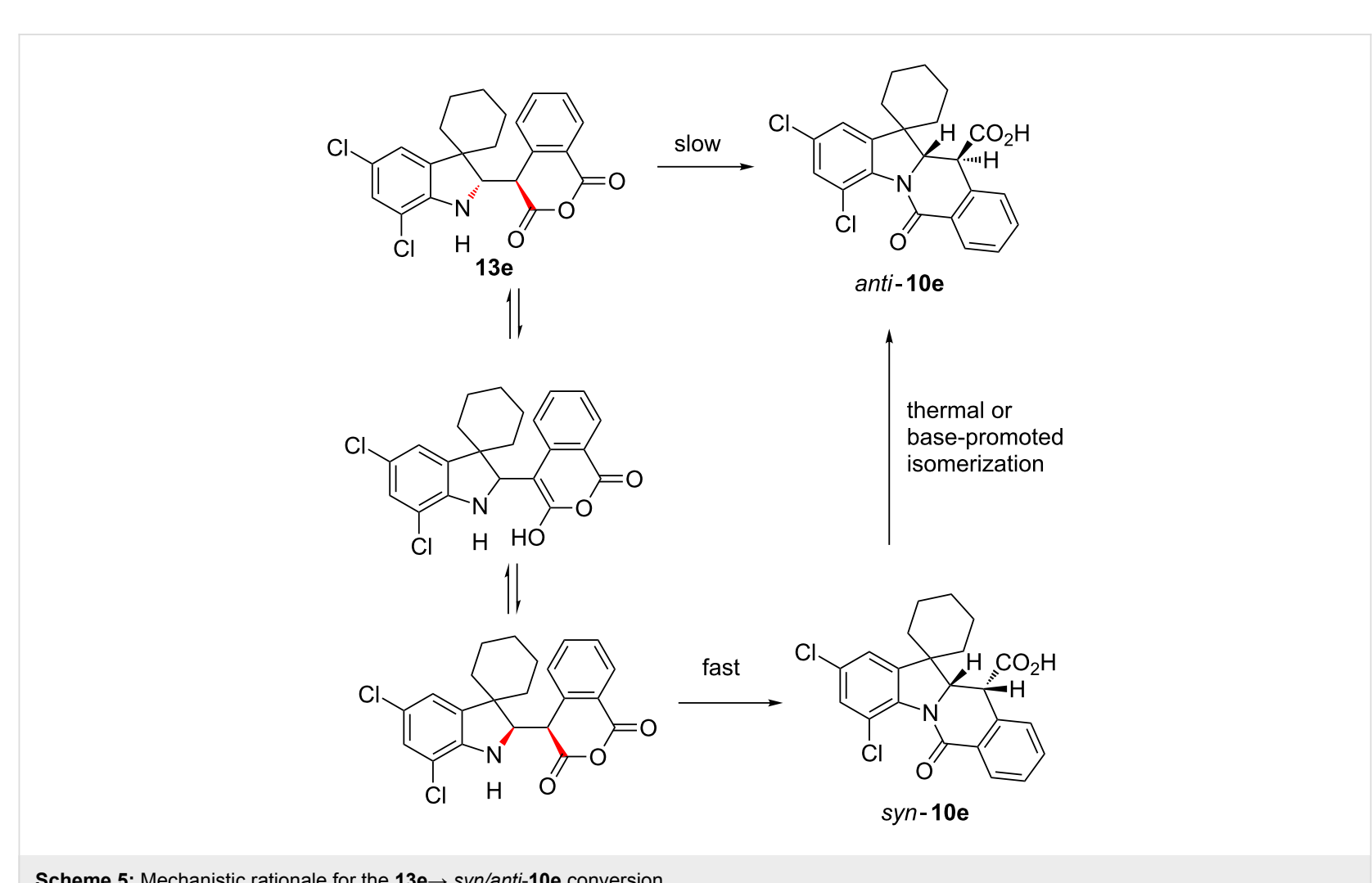




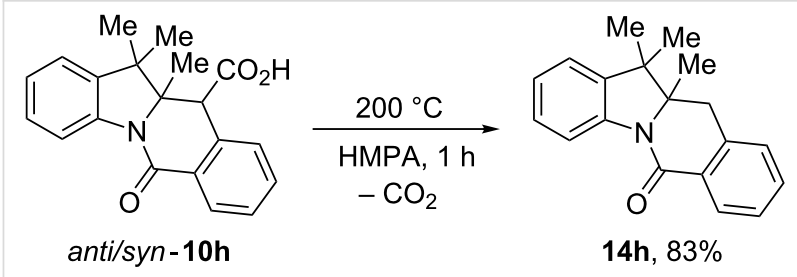

Scheme 6: Decarboxylation of antilsyn-10h. tary crystallographic data for this paper. These data can be obtained free of charge from The Cambridge Crystallographic Data Centre via http://www.ccdc.cam.ac.uk.

Indolenines 9. Indolenines 9a,b [26], 9d-g [26], 9h [36], 9i [37], 9j [38], 9k [39], 9p [40] are known compounds and were prepared from the arylhydrazine hydrochlorides and respective aldehydes or ketones according to the literature protocols.

pounds obtained contain a benzene-fused, privileged, naturally occurring hexahydropyrrolo[1,2- $b]$ isoquinoline core and are distinctly encumbered from steric perspective. The novel compounds have been characterized by NMR spectroscopy, highresolution mass spectrometry and X-ray crystallography and certain regularities in the NMR behavior have been established, leading a set of rules for stereochemical assignment based on the NMR data. A Mannich-type adduct between HPA and an imine (previously only postulated as a crucial intermediate en route to CCR products) has been isolated for the first time and fully characterized. Certain insights into the role of enolization equilibria in the formation and diastereomeric integrity of the CCR adducts has been obtained. The synthetic methodology described herein significantly expands the scope and tests the limits of the sterically permitted Castagnoli-Cushman reaction.

\section{Experimental}

General information. NMR spectroscopic data were recorded with a $400 \mathrm{MHz}\left(400.13 \mathrm{MHz}\right.$ for ${ }^{1} \mathrm{H}$ and $100.61 \mathrm{MHz}$ for ${ }^{13} \mathrm{C}$ ) and a $500 \mathrm{MHz}\left(500.03 \mathrm{MHz}\right.$ for ${ }^{1} \mathrm{H}$ and $125.7 \mathrm{MHz}$ for ${ }^{13} \mathrm{C}$ ) spectrometers in DMSO- $d_{6}$ or in $\mathrm{CDCl}_{3}$ and were referenced to residual solvent proton signals $\left(\delta_{\mathrm{H}}=7.26\right.$ and $2.50 \mathrm{ppm}$, respectively) and solvent carbon signals $\left(\delta_{C}=77.2\right.$ and $39.5 \mathrm{ppm}$, respectively). Coupling constants, $J$ are reported in Hz. Melting points were determined with an automated heat block instrument and are uncorrected. Mass spectra were recorded with a HRMS-ESI-qTOF spectrometer (electrospray ionization mode). $\mathrm{X}$-ray single crystal analyses were performed with monochromated Mo $\mathrm{K} \alpha$ or $\mathrm{Cu} \mathrm{K} \alpha$ radiation, respectively. Column chromatography was performed on silica gel 60 (230-400 mesh). For TLC analysis $\mathrm{UV}_{254}$ silica gel coated plates were used. $\mathrm{MeCN}$ was distilled from $\mathrm{P}_{2} \mathrm{O}_{5}$ and stored over molecular sieves $4 \AA$. Homophthalic anhydride was acquired from a commercial source, stored at $5{ }^{\circ} \mathrm{C}$ and used as received. All indolenines 9 were stored in sealed vials at $5{ }^{\circ} \mathrm{C}$ in the dark.

CCDC 1503093 (13e), 1503094 (anti-10c), 1503095 (anti-10d), 1503096 (anti-10g'), 1503097 (anti-10e), 1503098 (anti-10a'), 1503099 (anti-10f), 1503100 (syn-10a'), 1503101 (syn-10f), 1503102 (anti-10e'), 1503103 (anti-10n), 1503104 (anti-10i), 1503105 (syn-10e), 1503106 (anti-101), 1470399 (anti-10b), 1470389 (anti-10h), 1461790 (anti-10j) contain the supplemen-

\section{General procedure 1. Synthesis of indolenines $9 \mathrm{c}, \mathbf{l , n , 0 , q - t}$.} To a screw-cap vial containing suspension of corresponding arylhydrazine hydrochloride in glacial AcOH $(15 \mathrm{~mL})$ the carbonyl compound (1.1 equiv) was added in one portion. The reaction mixture was stirred at $55-60^{\circ} \mathrm{C}$ for $4 \mathrm{~h}$ (or at reflux for $2-16 \mathrm{~h}$ ) and concentrated in vacuo at $40{ }^{\circ} \mathrm{C}$. The residue was diluted with DCM $(50 \mathrm{~mL})$ and filtered through Celite. The resulting solution was passed through a short pad of silica, washed with sat. $\mathrm{NaHCO}_{3}$ and water. The organic layer was dried over $\mathrm{Na}_{2} \mathrm{SO}_{4}$ and concentrated under reduced pressure to give pure indolenines $\mathbf{9 c}, \mathbf{l}, \mathbf{s}$. Indolenines $9 \mathbf{9 n}, \mathbf{o}, \mathbf{q}, \mathbf{r}, \mathbf{t}$ were subjected to extra column chromatography.

General procedure 2. Synthesis of compounds 10. A mixture of homophthalic anhydride (1 equiv) and the corresponding indolenine 9a-t (1 equiv) was placed in a sealed screw-cap vial, dissolved in dry acetonitrile $(2 \mathrm{~mL}$ per $1 \mathrm{mmol})$ and stirred at room temperature for the time indicated in Table 1 . The reaction mixture was cooled to $-14{ }^{\circ} \mathrm{C}$, the resulting precipitate was filtered and washed with a minimum amount of cold acetonitrile to give pure compound $\mathbf{1 0}$.

General procedure 3. Synthesis of methyl esters $10^{\prime}$. The Castagnoli-Cushman product $\mathbf{1 0}$ was dissolved in dry acetone (10 mL per $1 \mathrm{mmol}$ ). Methyl iodide (2.5 equiv) and $\mathrm{K}_{2} \mathrm{CO}_{3}$ ( 2.5 equiv) were added to the solution and the resulting suspension was stirred for $24 \mathrm{~h}$ at room temperature. The volatiles were removed in vacuo. The residue was dissolved in DCM, washed with water, brine, dried over $\mathrm{Na}_{2} \mathrm{SO}_{4}$ and concentrated to give crude methyl ester $\mathbf{1 0}$ ', which was purified by column chromatography on silica gel.

\section{Supporting Information}

\section{Supporting Information File 1}

Detailed experimental procedures, analytical data and copies of ${ }^{1} \mathrm{H}$ and ${ }^{13} \mathrm{C}$ NMR spectra for all new compounds; crystallographic data for compounds 10 and 13e; results of correlational and variable temperature NMR experiments. [http://www.beilstein-journals.org/bjoc/content/ supplementary/1860-5397-13-138-S1.pdf] 


\section{Acknowledgements}

This research was supported by the Russian Scientific Fund (project grant 14-50-00069). NMR, mass spectrometry and $\mathrm{X}$-ray studies were performed at the Research Centre for Magnetic Resonance, the Centre for Chemical Analysis and Materials Research of Saint Petersburg State University Research Park and the Centre for X-ray Diffraction Methods. The authors are grateful to Dr. Sergey Miltsov for providing 2,3,3-trimethylindolenines employed in this study.

\section{References}

1. Krasavin, M.; Dar'in, D. Tetrahedron Lett. 2016, 57, 1635. doi:10.1016/j.tetlet.2016.03.021

2. Castagnoli, N., Jr. J. Org. Chem. 1969, 34, 3187. doi:10.1021/jo01262a081

3. Cushman, M.; Castagnoli, N., Jr. J. Org. Chem. 1973, 38, 440. doi:10.1021/jo00943a007

4. Adamovskyi, M. I.; Ryabukhin, S. V.; Sibgatulin, D. A.; Rusanov, E.; Grygorenko, O. O. Org. Lett. 2017, 19, 130. doi:10.1021/acs.orglett.6b03426

5. Bakulina, O.; Dar'in, D.; Krasavin, M. Synlett 2017, 28, 1165. doi:10.1055/s-0036-1588714

6. Wang, L.; Liu, J.; Tian, H.; Qian, C.; Sun, J. Adv. Synth. Catal. 2005, 347, 689. doi:10.1002/adsc.200404211

7. Mohammadi, M. H.; Mohammadi, A. A. Synth. Commun. 2011, 41, 523. doi:10.1080/00397911003611786

8. Karimi, A. R.; Momeni, H. R.; Pashazadeh, R. Tetrahedron Lett. 2012, 53, 3440. doi:10.1016/j.tetlet.2012.04.089

9. Humphries, P. S.; Benbow, J. W.; Bonin, P. D.; Boyer, D.; Doran, S. D.; Frisbie, R. K.; Piotrowski, D. W.; Balan, G.; Bechle, B. M.; Conn, E. L.; Dirico, K. J.; Oliver, R. M.; Soeller, W. C.; Southers, J. A.; Yang, X. Bioorg. Med. Chem. Lett. 2009, 19, 2400. doi:10.1016/j.bmcl.2009.03.082

10. Rothweiler, U.; Czarna, A.; Krajewski, M.; Ciombor, J.; Kalinski, C.; Khazak, V.; Ross, G.; Skobeleva, N.; Weber, L.; Holak, T. A. ChemMedChem 2008, 3, 1118. doi:10.1002/cmdc.200800025

11. Dar'in, D.; Bakulina, O.; Chizhova, M.; Krasavin, M. Org. Lett. 2015, 17, 3930. doi:10.1021/acs.orglett.5b02014

12. Liu, H.; Li, G.; Wang, J.; Liu, J. Corydaline derivatives useful for reducing lipid levels. PCT Int. Appl. WO2010075469, Dec 22, 2009. Chem. Abstr. 2010, 153, 145700.

13. Georgieva, A.; Stanoeva, E.; Spassov, S.; Macicek, J.; Angelova, O.; Haimova, M.; De Kimpe, N. Tetrahedron 1991, 47, 3375. doi:10.1016/S0040-4020(01)86402-4

14. Stanoeva, E.; Georgieva, A.; Avramova, S.; Burdzhiev, N.; Lázár, L. J. Heterocycl. Chem. 2015, 52, 130. doi:10.1002/jhet.1965

15. Smith, F. T.; DeRuiter, J.; Carter, D. A. J. Heterocycl. Chem. 1989, 26 , 1815. doi:10.1002/jhet.5570260653

16. Smith, F. T.; Atigadda, R. V. J. Heterocycl. Chem. 1991, 28, 1813. doi:10.1002/jhet.5570280728

17. Venkatram, A.; Colley, T.; DeRuiter, J.; Smith, F. J. Heterocycl. Chem. 2005, 42, 297. doi:10.1002/jhet.5570420220

18. Mulchandani, N. B.; Venkatachalam, S. R. Phytochemistry 1976, 15 , 1561. doi:10.1016/S0031-9422(00)88937-2

19. Padwa, A.; Brodney, M. A.; Lynch, S. M. J. Org. Chem. 2001, 66, 1716. doi:10.1021/jo0014109

20. Sun, Z.; Zhou, M.; Li, X.; Meng, X.; Peng, F.; Zhang, H.; Shao, Z. Chem. - Eur. J. 2014, 20, 6112. doi:10.1002/chem.201400178
21. Schramm, A.; Saxena, P.; Chlebek, J.; Cahlikova, L.; Baburin, I.; Hering, S.; Hamburger, M. Planta Med. 2014, 80, 740. doi:10.1055/s-0034-1368590

22. Wang, C.; Wang, Q.; Li, X.; Jin, X.; Xu, P.; Xu, N.; Xu, A.; Xu, Y.; Zheng, S.; Zheng, J.; Liu, C.; Huang, P. Biochem. Biophys. Res. Commun. 2017, 483, 197. doi:10.1016/j.bbrc.2016.12.168

23. Guo, Y.; Wang, Y.; Cao, L.; Wang, P.; Qing, J.; Zheng, Q.; Shang, L.; Yin, Z.; Sun, Y. Antimicrob. Agents Chemother. 2016, 60, 913. doi:10.1128/AAC.02274-15

24. Chen, C.-Y.; Zhu, G.-Y.; Wang, J.-R.; Jiang, Z.-H. RSC Adv. 2016, 6, 79958. doi:10.1039/c6ra16455b

25. Evans, B. E.; Rittle, K. E.; Bock, M. G.; DiPardo, R. M.; Freidinger, R. M.; Whitter, W. L.; Lundell, G. F.; Veber, D. F.; Anderson, P. S.; Chang, R. S. L.; Lotti, V. J.; Cerino, D. J.; Chen, T. B.; Kling, P. J.; Kunkel, K. A.; Springer, J. P.; Hirshfield, J. J. Med. Chem. 1988, 31, 2235. doi:10.1021/jm00120a002

26. Golubev, P.; Bakulina, O.; Dar'in, D.; Krasavin, M. Eur. J. Org. Chem. 2016, 3969. doi:10.1002/ejoc.201600656

27. Estévez, V.; Kloeters, L.; Kwietniewska, N.; Vicente-García, E.; Ruijter, E.; Orru, R. V. A. Synlett 2017, 28, 376. doi:10.1055/s-0036-1588084

28. Golubev, P.; Krasavin, M. Eur. J. Org. Chem. 2017, 1740. doi:10.1002/ejoc.201700152

29. Lovering, F.; Bikker, J.; Humblet, C. J. Med. Chem. 2009, 52, 6752. doi:10.1021/jm901241e

30. Ling, T.; Rivas, F. Tetrahedron 2016, 72, 6729. doi:10.1016/j.tet.2016.09.002

31. Luo, W.-K.; Shi, X.; Zhou, W.; Yang, L. Org. Lett. 2016, 18, 2036. doi:10.1021/acs.orglett.6b00646

32. Sarnpitak, P.; Krasavin, M. Tetrahedron Lett. 2014, 55, 2299. doi:10.1016/j.tetlet.2014.02.099

33. Georgieva, A.; Stanoeva, E.; Karafilova, K.; Spassov, S.; Angelova, O.; Haimova, M.; De Kimpe, N.; Boelens, M. Tetrahedron 1994, 50, 9399. doi:10.1016/S0040-4020(01)85515-0

34. Lepikhina, A.; Bakulina, O.; Dar'in, D.; Krasavin, M. RSC Adv. 2016, 6, 83808. doi:10.1039/C6RA19196G

35. Hong, J.; Wang, Z.; Levin, A.; Emge, T. J.; Floyd, D. M.; Knapp, S. Tetrahedron Lett. 2015, 56, 3001. doi:10.1016/j.tetlet.2014.10.027

36. Ji, C.; Ma, L.; Yin,, M.; Yang, W.; Pan, K. Chem. - Asian J. 2016, 11, 2316. doi:10.1002/asia.201600818

37. Szalóki, G.; Sanguinet, L. J. Org. Chem. 2015, 80, 3949. doi:10.1021/acs.joc.5b00282

38. Balmond, E. I.; Tautgeg, B. K.; Faulkner, A. L.; Or, V. W.; Hodur, B. M.; Shaw, J. T.; Louie, A. Y. J. Org. Chem. 2016, 81, 8744. doi:10.1021/acs.joc.6b01193

39. Schultz-Senft, M.; Gates, P. J.; Soennichsen, F. J.; Stanbitz, A. Dyes Pigm. 2017, 136, 292. doi:10.1016/j.dyepig.2016.08.039

40. Prostoba, Y.; Coelho, P. J.; Pina, J.; Seixas de Melo, J. J. Photochem. Photobiol., A: Chem. 2010, 216, 59. doi:10.1016/j.jphotochem.2010.09.006 


\section{License and Terms}

This is an Open Access article under the terms of the Creative Commons Attribution License

(http://creativecommons.org/licenses/by/4.0), which permits unrestricted use, distribution, and reproduction in any medium, provided the original work is properly cited.

The license is subject to the Beilstein Journal of Organic Chemistry terms and conditions:

(http://www.beilstein-journals.org/bjoc)

The definitive version of this article is the electronic one which can be found at:

doi:10.3762/bjoc. 13.138 